\title{
Rock blasting technology: The way forward
}

\author{
VR Sastry \\ National Institute of Technology Surathkal \\ Mangalore, India \\ vedala_sastry@nitk.edu.in
}

\section{INTRODUCTION}

Main objectives of rock blasting are to fragment the strata for achieving required yield with desirable fragmentation and minimum side effects. Though the side effects like ground vibrations, noise, fly rock, etc. cannot be avoided completely, these can be minimized by selecting suitable explosives, initiating devices and using proper blast design in given geo-mining conditions. Higher intensity of unwanted results indicates improper utilization of explosive energy in the fragmenting process, as the total amount of energy released by unit quantity of explosive is constant.

Energy released by an explosive, can be grouped into gaseous energy and shock energy, working on the surrounding strata resulting in fragmenting the medium through various rock breakage mechanisms. Normal approach to the assessment of blast results or explosives selection by the Indian Mining Industry even today is based on Conventional Powder Factor. Not much attention has been paid to analyze the blast results based on the fragmentation achieved, which in turn is related to energy utilization or wastage. Research findings established that in a properly designed blast, only around 15 to 20 per cent of the explosive energy is utilized and the remaining is wasted in generating side detrimental effects. Ineffective utilization of energy not only leads to improper fragmentation, but also results in side effects like venting out of explosive energy from stemming zone, generation of more ground vibrations and wastage of more seismic energy, etc. It is, therefore, very clear that even one percentage of additional positive utilization of explosive energy is a big contribution to the Indian Mining Industry.

The selection of explosives purely based on powder factor is not technically justifiable, as it takes into consideration only the quantity of muck pile generated, but not the quality of fragmentation (fragmentation size) and new surface area created, or wastage of energy, which are indicative of breakage effected by explosive energy in given geological conditions and for a given blast design.

Also there are significant advancements in the blasting technology in the form of instrumentation and softwares. However, these are hardly being used in the country due to various reasons. While there is a quantum jump in the usage of explosives in general in various sectors in the country, the utility of these technological developments for the furtherance of blasting activities is a pathetic minimum. An attempt is made through this presentation to analyse the blast performance in terms of ground vibrations, seismic energy, fragmentation analysis and specific surface area and the importance of the application of modern instrumentation and softwares in India in the present context, while policy makers are emphasising great advancements in mining and infrastructure industry, wherein blasting technology needs to be improved considerably. Some of the important areas which need more attention by all the concerned are being highlighted here.

\section{A) Explosive Energy}

Explosive energy is rated in a number of ways, obtained either from theoretical calculations or from experimental tests. However, it is very difficult to determine the amount of explosive energy transferred into the rock mass and converted into efficient work in the application of rock blasting. Although the measurement of some of the effects of the explosive energy in rock is customary (vibration, fragmentation and to some extent rock movement), they are usually conducted for blast control purpose, and the results are rarely cast in terms of their energy content. The reason for this may be that, it is not the energy consumption in this or that phenomenon that matters, but rather the end results, i.e. degree of fragmentation, throw and ground vibration levels. Data and estimations on energy components in rock blasting are thus limited to a few researchers. The seismic energy dissipated by a ground vibration event at a given distance from blast site could be a critical component in assessing performance of blasts, and it could be correlated with the fragmentation achieved in a given blast.

\section{B) High Speed Videography}

During the blast, events occur so rapidly that the human eye cannot judge the performance of individual elements of the blast progress and the elements involved like venting out of gaseous energy, performance of delays / initiation, burden rock movement etc. High speed videography with 500fps can provide an extended time base to study these elements. Information derived from the videos can help the blast designer to understand the explosive and geological dynamics involved, while reducing the number of costly 
field trials necessary to optimize the design and selection of explosives.

\section{C) Delay Timing}

Properly designed delays result in effective burden rock movement and minimize the superimposition of vibration wave forms generated from successive charges, in turn reducing the severity of ground vibrations and also the air blast. The rock or burden response of the blast and the post blast muck pile are also dependent on the timing sequence of the blast. Too little time between holes or rows results in a stacked muck pile that is difficult for the excavator to efficiently excavate.

Longer delays between holes may result in unsafe blasts creating excessive air blast levels and fly rock. In the selection of initiators, the precise number of milliseconds of time between initiator periods is important in rock breakage. Poor timing is a common occurrence which causes blast holes to malfunction. The initiation timing is one of the most easily corrected causes of malfunctioning of blast holes. High speed videography reveals the accurate information in order to design effective blasts.

\section{INVESTIGATIONS}

Research studies were carried out in different mines six coal and five limestone, for correlating the seismic energy dissipated by the blasts with fragmentation. High speed videography was used for analysing the burden rock movement, venting of gas energy through stemming zone, role of discontinuities in the wastage of gaseous energy, and finally to assess the performance of delays in blast rounds and the requirement of delay timings. Also an attempt was made to assess the potential of tapping electrical energy from the ground vibrations caused due to blasting operations in mines.

Fig. 1 shows progress of burden rock movement for a typical blast at different timings. This type of analysis is vital in identifying problem areas, and the zones to be given special importance while designing subsequent blasts. Escape of gas energy could be observed clearly from major bedding planes from Fig. 2. In fact, Fig. 2 shows a blast in which two different explosives were used in two halves of same block, and performance of two explosives in same formation was analysed in terms of better utilisation of explosive energy. It could be observed that the $2^{\text {nd }}$ half of blast (right side block) is not having much stemming ejection, while the $1^{\text {st }}$ half (left side block) is having prominent escape of gas energy from blastholes. This indicates unsuitability of explosive-A loaded in $1^{\text {st }}$ block in given formation. This interpretation is of significance in deciding the suitability of an explosive for given project, instead of going for mass procurement of a particular explosive for all the mines operating under single organisation.

Priming location is quite important for achieving good results from a given blast. It is normal practice to implement bottom priming. However, parameters like height of bench, structural discontinuities and other special techniques like air-decking may influence the movement of burden rock mass at different horizons in a bench. Knowledge about the relationship between energy generated within blasthole and the surrounding zones at different horizons, and burden rock movement is going to improve the performance of blasts, through selection of suitable primer location(s), especially in large opencast mines with taller benches.

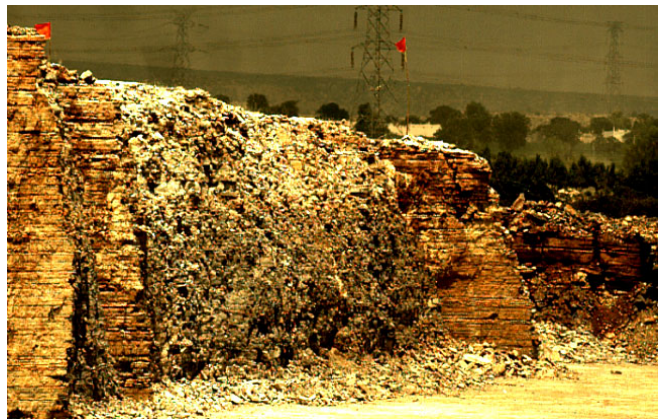

$0 \mathrm{~ms}$

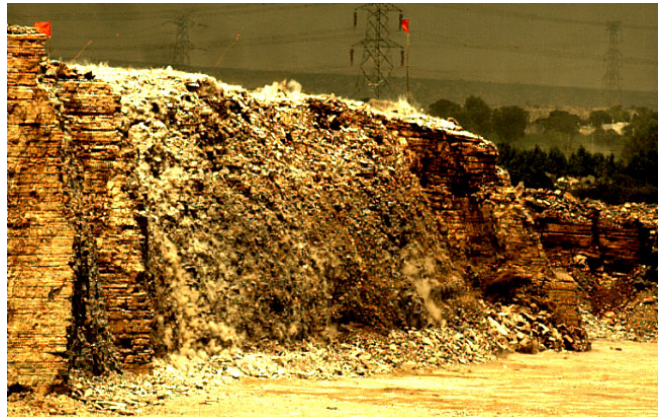

$400 \mathrm{~ms}$

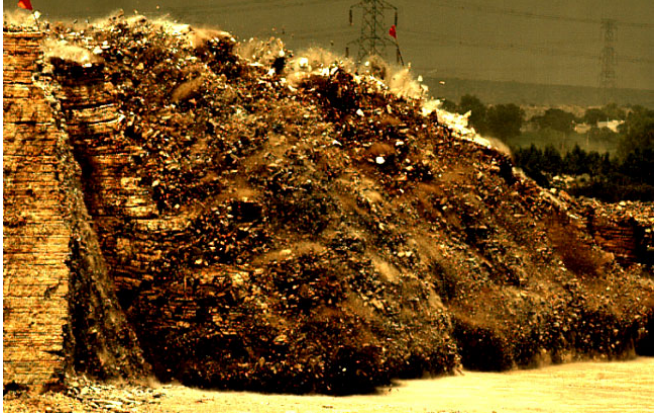

$600 \mathrm{~ms}$

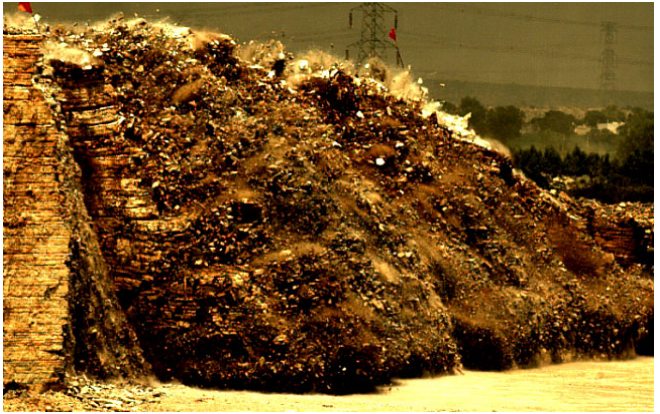

$800 \mathrm{~ms}$

Fig. 1 Progress of a typical blast 


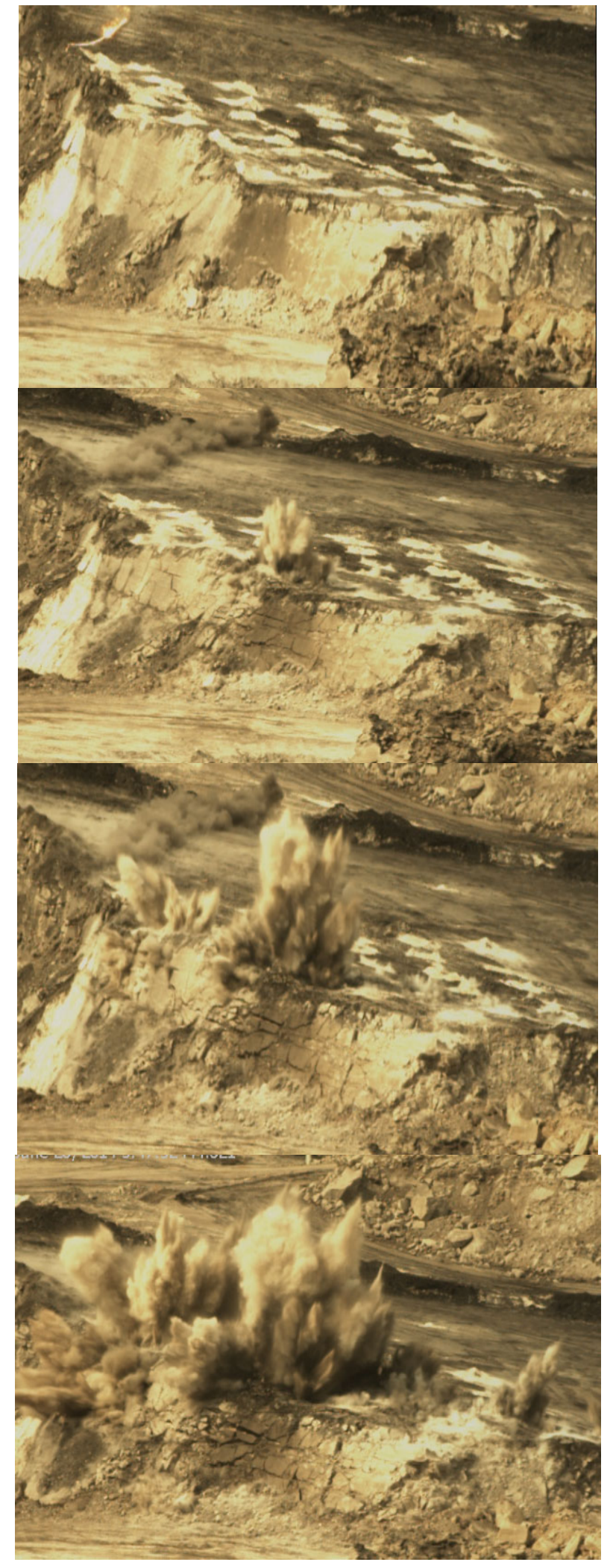

Fig. 2 Performance of two different explosives loaded in a single blast

Fig. 3 shows a typical analysis carried out in a limestone mine using high speed video camera and simulation of blasts using JK Sim Blast simulation software. Results of one of the mine on the relationship between rock mass movement and energy are shown in Fig. 4.

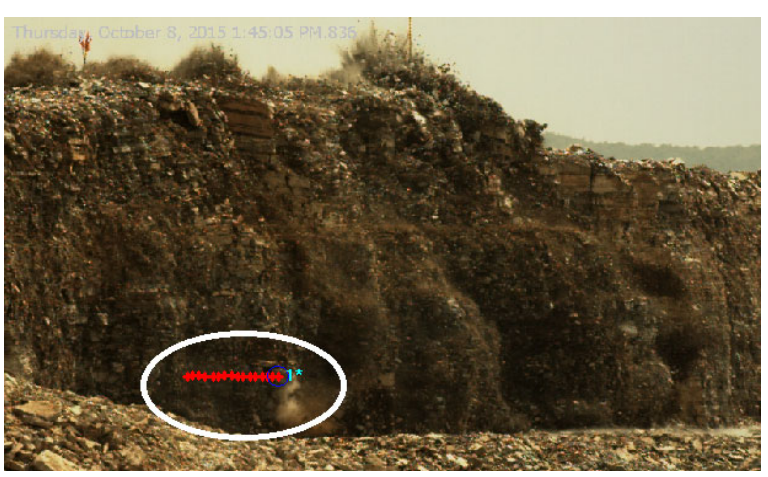

a.)Tracking of burden rock mass during blast

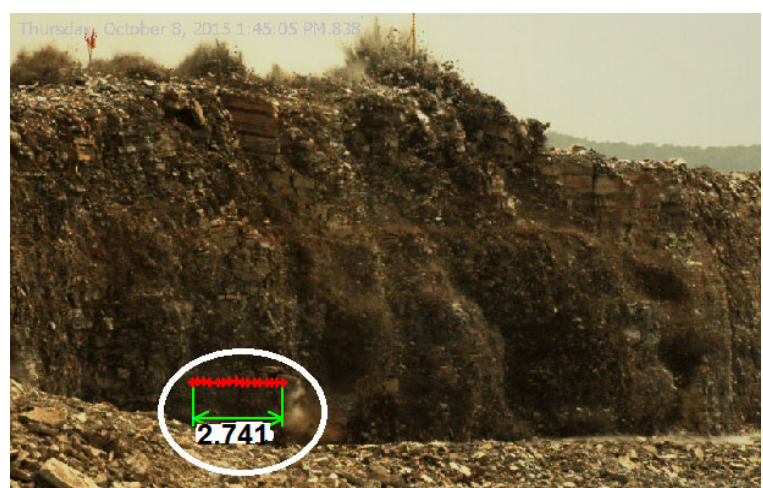

b.) Displacement of rock movement

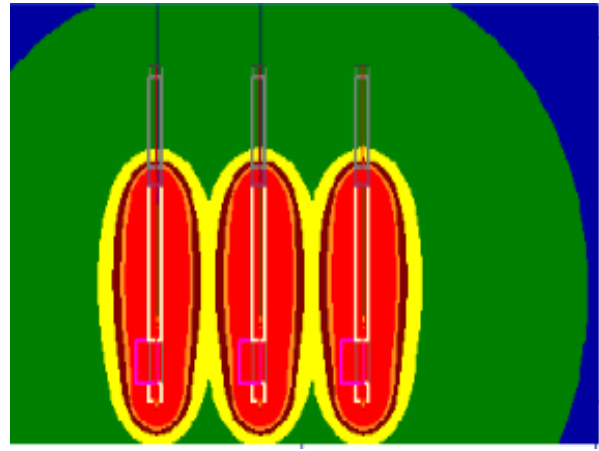

c.) Energy distribution in taller bench

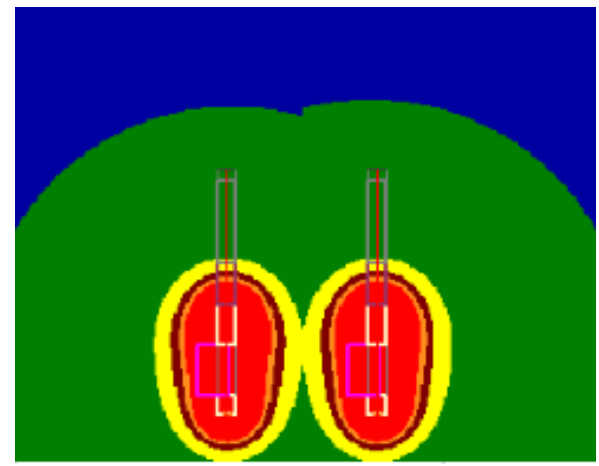

d.)Energy distribution inshorter bench

Fig. 3 Energy distribution \& rock movement in benches 


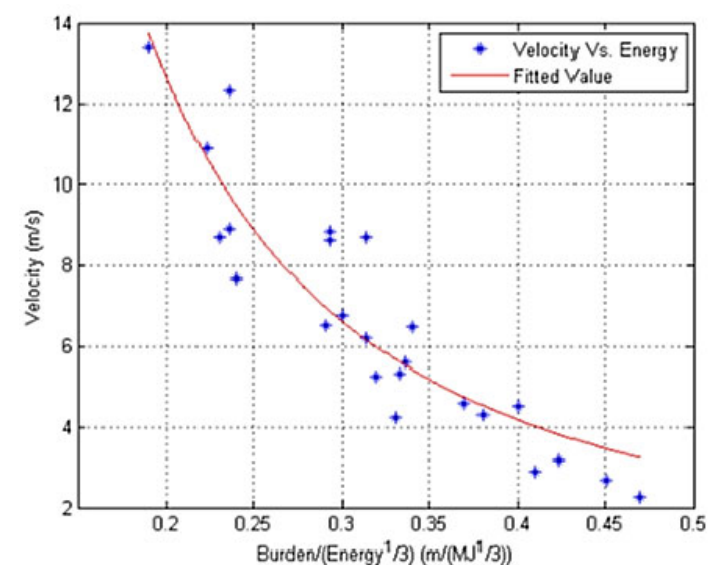

Fig. 4 Burden rock velocity Vs. Energy available

High speed videography is also useful in tracking down the venting out of gaseous energy through stemming zone and correlating this phenomenon with fragmentation achieved. Fig. 5 shows the relationship between stemming ejection and other parameters established in some coal mining projects.

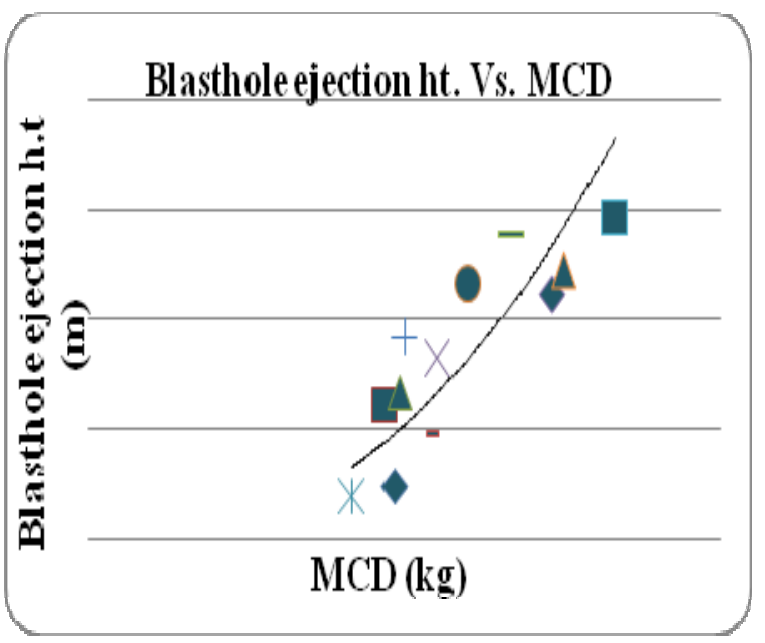

(a.)

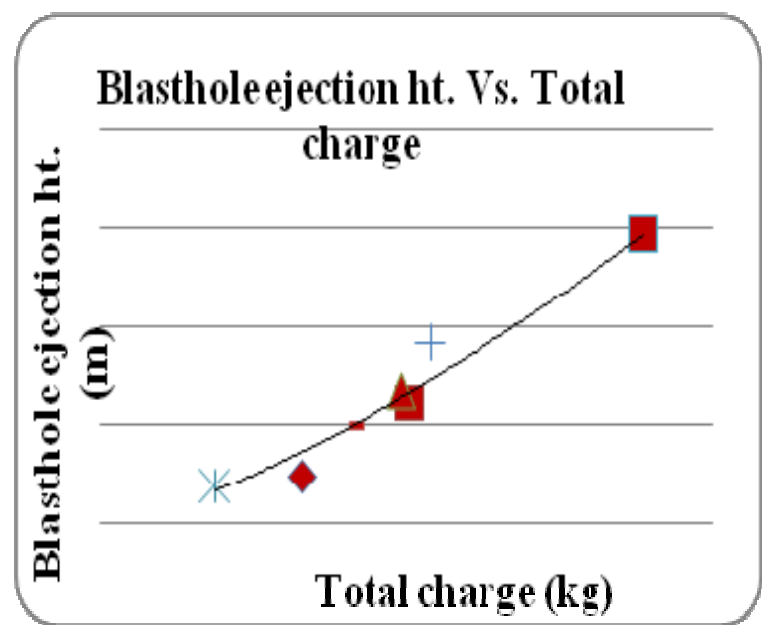

(b.)

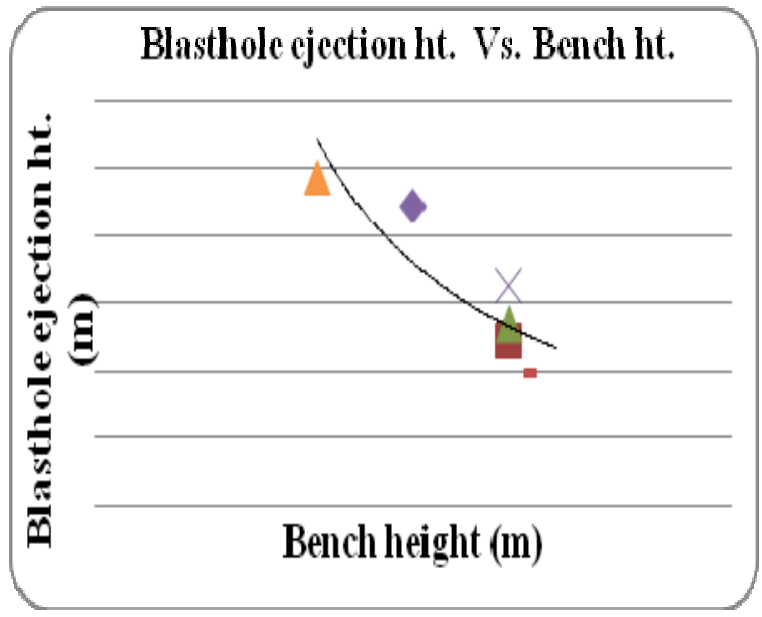

(c.)

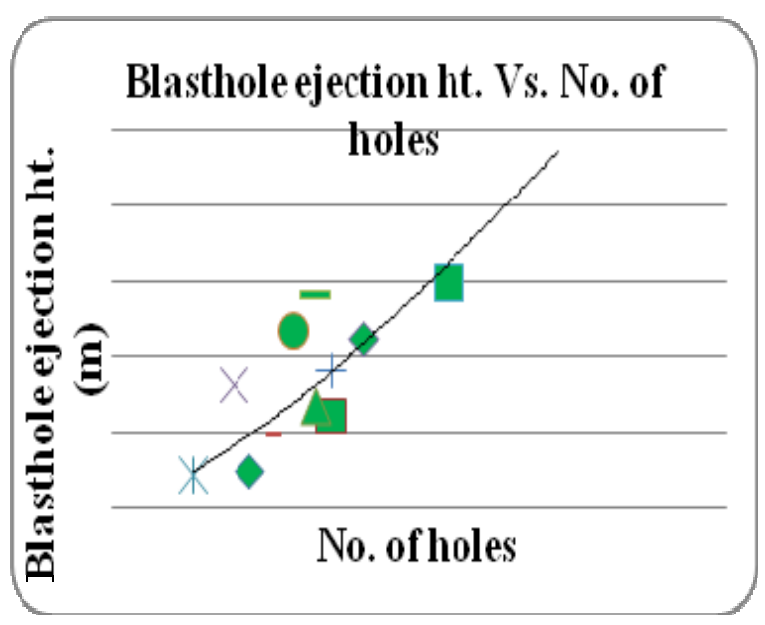

(d.)

Fig. 5 Relationship between stemming ejection and other parameters

D) Generation of Electrical Energy from Ground Vibrations

Ground vibrations carry seismic energy, a part of the wasted explosive energy in the blasting process. Intensity of ground vibrations varies from few hundreds of $\mathrm{mm} / \mathrm{s}$ at closed distances from the blast site to a few $\mathrm{mm} / \mathrm{s}$ at longer distances. There is a potential for tapping of electrical energy from the ground vibrations generated due to blasts carried out in mines and quarries using piezo sensors. Research work is initiated at NITK-Surathkal, focussing on tapping of electrical energy from undesirable ground vibrations using piezo sensor based circuit model. Whenever there is a compression of the ceramic PZT (lead ziconate titanate) sensor, a positive pulse of electricity is produced, whereas tension in the sensor unit gives rise to negative pulse. A microcontroller assisted Piezo-electric circuit was developed, and it was validated with ground vibration data at pilot scale, initially. Later, an LED was connected to the developed Piezo circuit in the circuit, which will glow whenever blast vibration is tapped and voltage is generated. The Piezo circuit was used in mines for tapping electrical energy from ground vibrations. Electrical Energy is calculated from the obtained voltage using following 
formula. Summary of tapped electrical voltage and electrical energy resulting from blast induced ground vibrations with microcontroller based piezo generator circuit model in a limestone formation is shown in Fig. 6. Data generated in the mine about seismic energy of ground vibration tapped at a given point and corresponding electrical energy tapped is presented in Table-1.

$$
\mathrm{E}=\frac{V^{2}}{R} t
$$

where,

$\mathrm{E}=$ Electrical energy $(\mathrm{J}$ or $\mu \mathrm{J})$

$\mathrm{V}=$ Electrical voltage tapped from ground vibrations

(V or $\mathrm{mV}$ )

$\mathrm{R}=$ Resistance of the circuit, $1 \Omega$

$\mathrm{t}=$ Time period of tapped vibration (s)

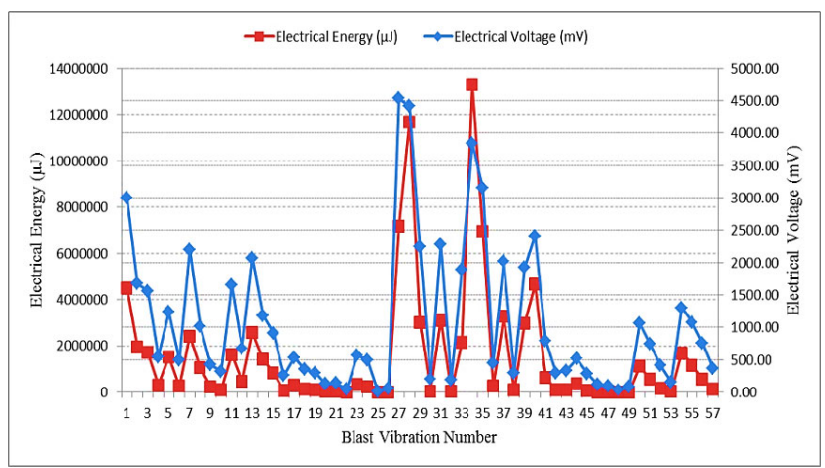

Fig. 6 Summary of tapped electrical voltage and electrical energy in limestone formation with microcontroller based piezo generator circuit

\section{E) Blast Fragmentation Analyser}

Measuring the size distribution of blasted rock muck pile is a complicated process due to the presence of wide range of fragment sizes and the difficulty in obtaining statistically reliable samples of the material. The software being developed by us indigenously would help to measure different grain sizes in a granular material mass, based on analysing a photograph and create statistics based on what the picture portrays. The software is developed using Java and MATLAB toolbox. Typical comparison of results from Wipfrag and currently developed software for a given blast are presented in Table-2. Advantages of our software being developed over WIPFRAG, very commonly used software for fragmentation assessment are given below:

- Automated application - No manual profiling is required.

- Automated calibrating of the image very accurately

- $\quad$ Time required for processing per image is very less, a few minutes instead of few days. Parallel processing of images increases efficiency of the system.

- User friendly Web Interface.

- Freeware application compared to other expensive counterparts like WIPFRAG
TABLE I SUMMARY OF SEISMIC ENERGY AND ELECTRICAL ENERGY OBTAINED IN SANDSTONE FORMATION

\begin{tabular}{|c|c|c|c|c|}
\hline $\begin{array}{l}\text { Sl. } \\
\text { No }\end{array}$ & $\begin{array}{l}\text { Dist. } \\
\text { (m) }\end{array}$ & $\begin{array}{c}\text { Scaled } \\
\text { Distance } \\
(\mathrm{m} / \sqrt{\mathrm{kg}})\end{array}$ & $\begin{array}{c}\text { Seismic Energy } \\
(\mu J)\end{array}$ & $\begin{array}{c}\text { Electrical Energy } \\
(\mu \mathrm{J})\end{array}$ \\
\hline 1 & 100 & 12.31 & 2738832.38 & 3659414.94 \\
\hline 2 & 110 & 13.54 & 1511665.32 & 3439512.65 \\
\hline 3 & 120 & 14.77 & 1470468.86 & 3395392.29 \\
\hline 4 & 150 & 18.46 & 6916156.65 & 3180444.76 \\
\hline 5 & 160 & 19.69 & 5245447.10 & 6673691.18 \\
\hline 6 & 170 & 20.93 & 8461652.43 & 9661865.74 \\
\hline 7 & 184 & 26.02 & 1562458.55 & 3269370.34 \\
\hline 8 & 178 & 18.97 & 9277651.80 & 10758291.55 \\
\hline 9 & 188 & 20.04 & 4747405.68 & 6231893.85 \\
\hline 10 & 200 & 21.32 & 366544.54 & 1158347.87 \\
\hline 11 & 150 & 16.27 & 10544797.69 & 12532839.03 \\
\hline 12 & 209 & 22.67 & 2280225.67 & 2166323.13 \\
\hline 13 & 234 & 25.38 & 1055142.78 & 937364.56 \\
\hline 14 & 696 & 32.81 & 513484.49 & 563178.40 \\
\hline 15 & 603 & 28.12 & 1980472.55 & 2324044.37 \\
\hline 16 & 636 & 29.65 & 160142.93 & 800497.02 \\
\hline 17 & 220 & 22.00 & 8769781.29 & 10409916.18 \\
\hline 18 & 380 & 38.00 & 172599.58 & 672964.28 \\
\hline 19 & 304 & 32.04 & 638174.00 & 1294450.03 \\
\hline 20 & 332 & 35.00 & 164876.00 & 549587.49 \\
\hline 21 & 379 & 39.95 & 61901.33 & 681376.33 \\
\hline 22 & 280 & 28.00 & 615873.46 & 1192184.45 \\
\hline 23 & 290 & 29.00 & 73406.11 & 636926.93 \\
\hline
\end{tabular}

TABLE II COMPARISON OF FRAGMENTATION ASSESSMENT

\begin{tabular}{|l|l|c|}
\hline Size (mm) & \% Passing (WipFrag) & \% Passing (Current) \\
\hline 1000.00 & 100.00 & 100.00 \\
\hline 500.00 & 100.00 & 99.63 \\
\hline 300.00 & 89.95 & $9^{7} .69$ \\
\hline 150.00 & 68.03 & 88.42 \\
\hline 125.00 & 60.42 & 33.96 \\
\hline 100.00 & 54.06 & 78.63 \\
\hline 75.00 & 48.59 & 70.94 \\
\hline 50.00 & 38.12 & 58.68 \\
\hline 40.00 & 31.81 & 53.50 \\
\hline 37.50 & 29.48 & 52.12 \\
\hline 3530 & 28.29 & 50.58 \\
\hline 31.50 & 23.61 & 47.53 \\
\hline 25.00 & 16.45 & 40.05 \\
\hline 16.00 & 7.71 & 26.72 \\
\hline 12.50 & 4.89 & 26.72 \\
\hline 10.00 & 2.92 & \\
\hline & & 26.72 \\
\hline
\end{tabular}




\section{CONCLUSION}

Usage of explosive energy in mines and construction projects is increasing significantly in the country. Basis for the procurement of explosives should be deviated from the age-old Powder Factor concept, to more scientifically based energy utilisation criteria. Parameters like wastage of seismic energy through ground vibrations, wastage of gaseous energy through stemming ejection; burden rock movement, etc. could be the main parameters, in addition to the fragmentation, for judging the performance of explosives. Tapping electrical energy from unwanted ground vibrations offers another new potential area of research, wherein there is a possibility of replacing the conventional ground vibration recorders with piezo-electric circuit based instruments which result in tremendous cost cut down making the units more affordable by all, in addition to tap electrical energy to run at least VLSI systems. Salient features of the research carried out are summarised below for the benefit of the industry.

- High speed video camera is an excellent tool for analysing the blast results and designing efficient blasts.

- Study based on high speed videography revealed that in taller benches, the delay between holes/rows could be $8 \mathrm{~ms}$ per metre distance. In case of shorter benches the delay time required is about $12 \mathrm{~ms}$ per metre distance, contrary to the present practice of using $17 \mathrm{~ms}, 25 \mathrm{~ms}$ or $42 \mathrm{~ms}$ standard delays or less than that.

- In general, the rock movement is higher at the centre of the bench. However, in taller benches, the high-speed videography analysis showed maximum movement of the burden rock shifting towards toe portion of the bench, which is very much desirable. It is, therefore, advisable to adopt taller benches instead of shorter benches.

- With increase in MCD and total charge, the height of blast hole ejection increased, indicating increased wastage of Gas Energy.

- The relationship was established between the energy and burden rock movement that could be applicable for limestone mines.

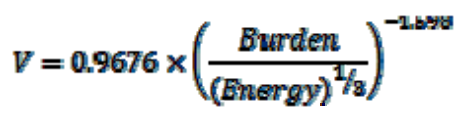

where, ' $\mathrm{v}$ ' is velocity of burden rock mass in $\mathrm{m} / \mathrm{s}$, ' $\mathrm{E}$ ' is Energy around blast hole is in kcal and Burden in $\mathrm{m}$.

- The actual initiation timing (in the field) was found to vary by around $23 \%$ (lowest) to $100 \%$ (highest) from the designated delays. In general, it was observed from high speed videography, that the percentage of error in delay time performance, even with shock tube system of initiation, was ranging between $40 \%$ and $80 \%$, which is quite significant and detrimental to the performance of blast rounds.

- The electrical energy tapped from ground vibrations is up to $13,291,238 \mu \mathrm{J}$ in limestone, $38,497,572 \square \mathrm{J}$ in sandstone and 599,437,080 $\square \mathrm{J}$, in granite formations. Electrical energy generated from the seismic waves was used to run a LED connected across Capacitor and small PCB based circuit (low powered VLSI based circuit or ambient power based load).

- Working of piezo sensor in tapping ground vibrations is found to be as accurate as a standard imported blast vibration monitor, which could have commercial value based on further studies.

- There is great need to use digital image processing based fragmentation assessment softwares for gauging the performance of blasts in mines and other major construction projects in terms of fragmentation. Efforts are on to develop an Indigenous Software which is as accurate as Wipfrag, and quite economical and affordable to even small players in mining industry.

\section{ACKNOWLEDGEMENT}

The Author is thankful to the management of Coal India Limited for funding the research project on "Assessment of Explosive Performance / Blasts based on Energy Utilisation". Thanks are due to the Central Mine Planning \&Design Institute Limited, Mahanadi Coalfields Limited and The Singareni Collieries Company Limited for extending all facilities for carrying out research studies. Views expressed in this paper are of the author and need not reflect the views of the organisations mentioned. 